\title{
CATALYTIC COMBUSTION OF SOOT ON Ce-DOPED LANTHANUM COBALTITES
}

\author{
GINA PECCHI ${ }^{*}$, RUDDY MORALES ${ }^{1}$, EDUARDO J. DELGADO ${ }^{1}$, ROMEL JIMENEZ ${ }^{2}$, MARCO FRAGA
}

\author{
I: Departamento Físico-Química, Facultad Ciencias Químicas; ${ }^{2}$ : Departmento Ingeniería Química, Facultad de Ingeniería, Universidad de Concepción, Con-
} cepción, Chile. ${ }^{3}$ : Instituto Nacional de Tecnologia / MCTI,Rio de Janeiro, Brasil.

\begin{abstract}
Substituted $\mathrm{La}_{1-\mathrm{x}} \mathrm{Ce}_{\mathrm{x}} \mathrm{CoO}_{3}$ perovskite-type oxides $(0.0 \leq \mathrm{x} \leq 0.9)$, prepared by the self-combustion method, have been investigated as catalysts in soot combustion. The characterization results indicate modification in the specific surface area, crystal structure, oxygen mobility and reducibility of cobaltite upon cerium substitution. Cobaltite structure does not tolerate more than $50 \%$ substitution of La by Ce. For higher Ce substitution the perovskite structure is lost and mixed oxides are detected. Further destruction of the perovskite structure in a reductive process indicates a lower catalytic role of the perovskite structure in the catalytic combustion of soot regarding to the chemical composition of the $\mathrm{La}_{1-\mathrm{x}} \mathrm{Ce}_{\mathrm{x}} \mathrm{CoO}_{3}$ system. After the reductive process, only a slight increase in the catalytic activity of the samples with low Ce content $(x \leq 0.3)$ while a larger increased was detected for those with larger amount of $\mathrm{Ce}(\mathrm{x} \geq 0.5)$. These results suggest that the activity of these materials for soot combustion is improved by two factors: i) the increasing of $\mathrm{CeO}_{2}$ content, closely related to higher material capacity for oxygen transfer from catalyst to carbonaceous surface and ii) the formation of larger $\mathrm{CeO}_{2}$ crystals in the higher-Ce-content samples after $\mathrm{H}_{2}$ reduction, responsible of the improvement of the oxygen exchange and number of contact points between catalyst and soot.
\end{abstract}

Keywords: cobalt, ceria, lanthanum, perovskite, soot, combustion

\section{INTRODUCTION}

Diesel engines play a vital role in the modern society since they are widely used in heavy-duty transportation and power generation. The application of diesel engines in these fields is motivated because of the high efficiency of the engines, their low-operating costs, high durability and reliability. However, the diesel engine is one of the largest contributors to environment pollution problems worldwide, and will remain so, with large increases expected in vehicle population causing ever-increasing global emissions of diesel particulate matter and nitrogen oxides. Particulate matter consists mostly of carbonaceous soot with minor components of volatile organic fraction, from unburned fuel, and inorganic compounds such as ash and sulphur compounds. The particulate material is responsible for serious adverse effects on human health, physiology of plants, environment, building materials and global warming. For these reasons, legislative restrictions for emission levels have stimulated the development of new catalysts and technologies for the abatement of soot particulates. Among the traditional catalytic systems for soot combustions such as noble metals[1], oxides and mixed oxides[2], alkali based materials[3]; perovskite-type mixed oxides have received recently considerable attention for this purpose[4-8]. Perovskite-type oxides are represented by the general formula $\mathrm{ABO}_{3}$, where the A-site metal is usually a rare earth element, and the B-site metal is a first row transition metal. Due to the number of possible combinations of metals for the A and B-sites, perovskites can be tailored to create a wide family of catalysts, by varying either the A-site and/or the B-site metal ion. Thus, pure and doped lanthanum chromites, manganites and cobaltites, have been tested with mixed results in the catalytic combustion of soot [9]. Recently, a $\operatorname{Pr}_{07} \mathrm{Sr}_{02} \mathrm{~K}_{01} \mathrm{MnO}_{3}$ perovskite type catalyst on a ceramic filter has been point out has a promising soot catalyst and that more detailed investigations must be carried out to understand their catalytic behavior [10]. Cerium is usually reported as a good promoter in perovskite lattice. Partial substitution of lanthanum by cerium or strontium on cobalt based perovskites leads to an increase in catalytic oxidation [11]. When perovskite-type oxides are submitted to a reduction process, the low thermal behavior of these materials under reductor atmosphere allow to produce nanometric metal particles, in a high dispersion degree [12] modifying the oxygen storage capacity of the catalyst. The substitution of the lanthanum cation $\mathrm{La}^{3+}$ by an oxygen storage cation as cerium, with the capacity of the redox $\mathrm{Ce}^{3+} / \mathrm{Ce}^{4+}$ couple, must have a direct effect in the reducibility of the perovskite structure and dispersion degree of the pure or mixed $\mathrm{La}_{2} \mathrm{O}_{3}$ and $\mathrm{CeO}_{2}$ oxides.

In this article it is proposed to use calcined and reduced Ce-doped lanthanum cobaltite's; $\mathrm{La}_{\mathrm{x}} \mathrm{Ce}_{1-\mathrm{x}} \mathrm{CoO}_{3}, \mathrm{x}=0.1 \rightarrow 0.9$ on the catalytic combustion of soot. The synthesis, characterization and the effect of reduction and substitution degree on the catalytic activity is reported.

\section{MATERIAL AND METHODS}

2.1 Preparation

Pure cobaltite $\left(\mathrm{LaCoO}_{3}\right)$ and substituted $\mathrm{La}_{1-1} \mathrm{Ce} \mathrm{CoO}_{3}(\mathrm{x}=0.1,0.3,0.5$, $0.7,0.9)$ catalysts were prepared by the self-combustion method [13]. Glycine $\left(\mathrm{H}_{2} \mathrm{NCH}_{2} \mathrm{CO}_{2} \mathrm{H}\right)$, used as ignition promoter, was added to an aqueous solution of metal nitrates with the appropriate stoichiometry in order to get a $\mathrm{NO}_{3}{ }^{-}$ $\mathrm{NH}_{2}($ molar ratio $)=1$. The resulting dissolution was slowly evaporated until a vitreous green gel was obtained. The gel was heated up to around $250^{\circ} \mathrm{C}$, temperature at which the ignition reaction occurs producing a powdered precursor. The solids were crushed and sieved to obtain the required particle size $(<200$ $\mu \mathrm{m})$ prior to calcination at $700^{\circ} \mathrm{C}$ in air for $10 \mathrm{~h}$ to eliminate the remaining carbon. Even though in some of the calcined solids the perovskite structure is not reached, for uniformity it has been maintained the nomenclature $\mathrm{La}_{1-\mathrm{x}} \mathrm{Ce}_{\mathrm{x}-\mathrm{x}}$ $\mathrm{CoO}_{3}$. To study the thermal stability in hydrogen, the calcined perovskites were reduced under pure hydrogen flow $\left(50 \mathrm{mLmin}^{-1}\right)$ at $500^{\circ} \mathrm{C}$ for $2 \mathrm{~h}$. After, the reactor was purged with nitrogen and cooled down to room temperature, placed in a cryostatic bath and a flow of $5 \% \mathrm{O}_{2} / \mathrm{Ar}$ was admitted into the reactor for $1 \mathrm{~h}$. Afterwards, it was purged for 30 min with $\mathrm{N}_{2}$ under the same cryostatic conditions and finally the bath was removed and the catalysts were stabilized at room temperature. These materials are referred as reduced samples in this paper.

2.2 Characterization

Chemical analysis of the samples was carried out by atomic absorption spectroscopy (AAS) using a Perkin Elmer instrument model 3100. Samples were dissolved in $\mathrm{HCl}$ and $\mathrm{HNO}_{3}$ acids dissolutions and then appropriately diluted to get concentrations of lanthanum, cerium and cobalt within the calibration range of the instrument. Specific surface (SS) areas were calculated using the BET method from the nitrogen adsorption isotherms, recorded at $77 \mathrm{~K}$ on a Micromeritics apparatus Model ASAP 2010. X-ray powder diffraction (XRD) patterns were obtained with nickel-filtered $\mathrm{CuK} \alpha_{1}$ radiation $(\lambda=1.5418 \AA)$ using a Rigaku diffractometer controlled by a computer. TPD-O experiments were performed in a TPR/TPD 2900 Micromeritics system with a thermal conductivity detector. The samples were exposed to oxygen for $1 \mathrm{~h}$ at $600^{\circ} \mathrm{C}$, followed by cooling to room temperature in the same atmosphere. After switching the atmosphere to a helium flow, the sample was heated at a constant rate of $10^{\circ} \mathrm{Cmin}^{-1}$ and the desorbed oxygen was monitored with a thermal conductivity detector. Temperature programmed reduction (TPR) experiments were performed in a TPR/TPD 2900 Micromeritics system with a thermal conductivity detector. Samples were placed in a U-shape quartz tube and purged in a synthetic air stream of $50 \mathrm{mLmin}^{-1}$ at $500^{\circ} \mathrm{C}$ for $1 \mathrm{~h}$ and then cooled to ambient temperature. A cold-trap was placed just before the TCD of the instrument to remove the water from the exit stream.

2.3 Catalytic activity

The catalytic activity of the solids was investigated using carbon black (CB) as model of soot. The catalyst-CB mixture for the assessment of the catalytic activity was prepared mixing $4 \mathrm{mg}$ of $\mathrm{CB}$ and $16 \mathrm{mg}$ of catalyst in tight 
contact. The catalytic oxidation of the $\mathrm{CB}$ was carried out in a thermogravimetric apparatus (Netzch 409 PC) with $7.5 \mathrm{mg}$ of the mixture heated in 180 $\mathrm{mLmin}^{-1}$ flow of air at $10^{\circ} \mathrm{Cmin}^{-1}$ up to $800^{\circ} \mathrm{C}$. The combustion rate was normalized dividing by the initial weight of $\mathrm{CB}$ in each sample. The temperature at which combustion occurs at the maximum rate, denoted as Tm, and the catalytic activity index (CAI) defined as the difference between the temperatures for the catalyzed and uncatalyzed reaction, that is: $\mathrm{CAI}=(\mathrm{Tm})_{\text {uncat }}-(\mathrm{Tm})_{\text {cat }}$ was taken as a measure of catalytic activity[14].

\section{RESULTS}

3.1 Catalytic Activity

Figure 1 shows the DTG curves for CB combustion of the calcined (solid line) and reduced (dotted line) solids. The catalytic activity is estimated from the temperature corresponding to the maximum of DTG curve, Tm. Higher values for Tm means lower catalytic activity. The Tm for the uncatalized CB combustion is $650^{\circ} \mathrm{C}$, so all tested samples exhibit a significant catalytic activity; even the less active solid, $\mathrm{LaCoO}_{3}$, decreases the Tm value in about $200^{\circ} \mathrm{C}$. It is also observed that the catalytic activity of calcined samples (solid lines) increases with the increase of the cerium content in the catalyst, and the higher CAI is observed for $\mathrm{La}_{0.1} \mathrm{Ce}_{0.9} \mathrm{CoO}_{3}$, which is the sample with the highest Ce/ La mass ratio (Fig. 1).

In order to evaluate the effect of perovskite-type structure on $\mathrm{CB}$ combustion reaction rate, the calcined samples were reduced in $\mathrm{H}_{2}$ at $700^{\circ} \mathrm{C}$ to destroy the perovskite structure. After that, the samples were again tested as catalyst for $\mathrm{CB}$ combustion (Fig. 1, dotted lines). It is observed that the reduction process did not significantly affect the catalytic activity of low-Ce-content samples $(x=0,0.1,0.3)$, while an important decrease of Tm value was observed for those samples with higher Ce content, which burned the soot at temperatures as lower as $354^{\circ} \mathrm{C}$.Fig. 1 also shows that for the reduced samples with higher Ce content $(\mathrm{x}=0.5,0.7,0.9)$ not only the Tm values decrease but also the maximum reaction rate for $\mathrm{CB}$ combustion increases. On the other hand, the lower La content in the catalysts the higher CAI value for both calcined and reduced samples (Fig.1, Table 1).

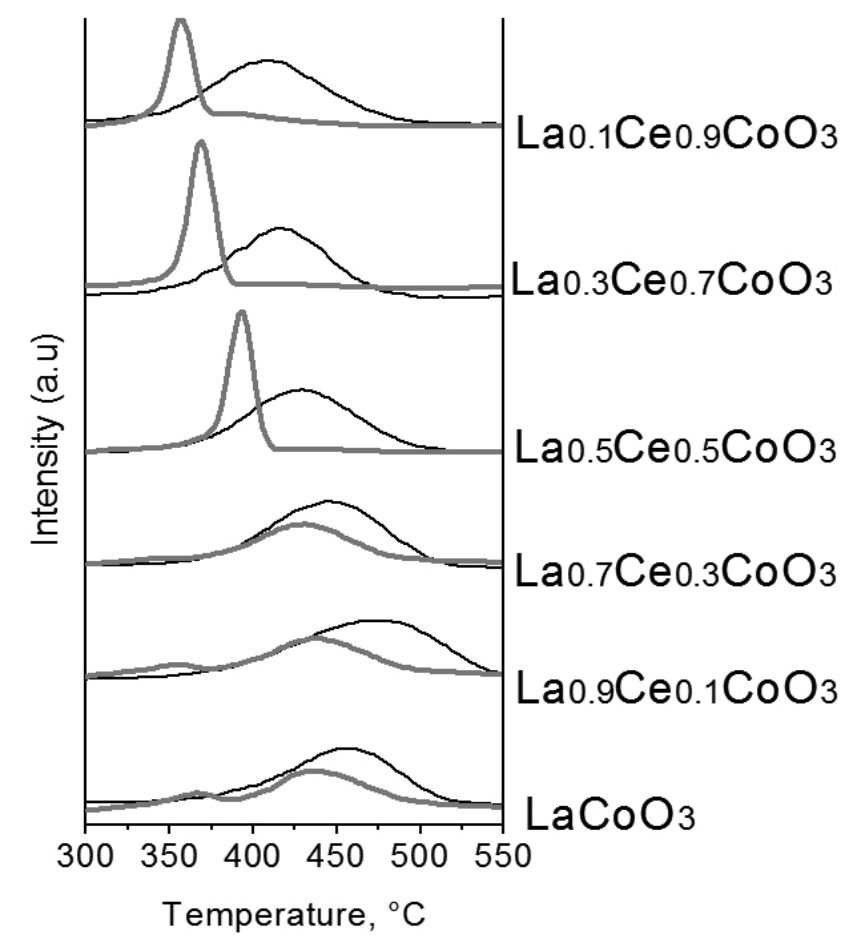

Figure 1. Thermogravimetric assays for the catalytic combustion of CB. (-) calcined, (一) reduced.
Table 1: $\mathrm{Tm}$ for $\mathrm{La}_{1-\mathrm{x}} \mathrm{Ce}_{\mathrm{x}} \mathrm{CoO}_{3}$ catalysts. $\mathrm{Tm}=650^{\circ} \mathrm{C}$ for uncatalyzed $\mathrm{CB}$ combustion.

\begin{tabular}{|c|c|c|c|c|c|}
\hline & \multirow{2}{*}{} & $\mathrm{x}_{\mathrm{Ce}}$ & \multicolumn{2}{|c|}{$\mathrm{Tm},{ }^{\circ} \mathrm{C}$} & \multicolumn{2}{c|}{$\mathrm{CAI},{ }^{\circ} \mathrm{C}$} \\
\cline { 3 - 6 } & & calcined & reduced & calcined & reduced \\
\hline $\mathrm{LaCoO}_{3}$ & 0.0 & 454 & 437 & 200 & 213 \\
\hline $\mathrm{La}_{0.9} \mathrm{Ce}_{0.1} \mathrm{CoO}_{3}$ & 0.1 & 476 & 438 & 174 & 212 \\
\hline $\mathrm{La}_{0.7} \mathrm{Ce}_{0.3} \mathrm{CoO}_{3}$ & 0.3 & 445 & 429 & 205 & 221 \\
\hline $\mathrm{La}_{0.5} \mathrm{Ce}_{0.5} \mathrm{CoO}_{3}$ & 0.5 & 430 & 390 & 220 & 260 \\
\hline $\mathrm{La}_{0.3} \mathrm{Ce}_{0.7} \mathrm{CoO}_{3}$ & 0.7 & 415 & 369 & 235 & 281 \\
\hline $\mathrm{La}_{0.1} \mathrm{Ce}_{0.9} \mathrm{CoO}_{3}$ & 0.9 & 405 & 354 & 245 & 296 \\
\hline
\end{tabular}

\subsection{Elemental composition}

The Atomic Absorption Spectroscopy composition of the $\mathrm{La}_{1-x} \mathrm{Ce}_{\mathrm{x}} \mathrm{CoO}-$ ${ }_{3}$ samples shown in Table 2 indicatesthat experimental lanthanum, cerium and cobalt contents approach to the nominal ones.

\subsection{Specific area}

The BET areas of the calcined and reduced solids are summarized in Table 2. It can be seen that the reduction process decreases the surface area of the solids. The reduced cobaltite and the one with lower Ce content $(x=0.1)$ exhibits the lowest $\mathrm{S}_{\mathrm{BET}}$, of $7 \mathrm{~m}^{2} \mathrm{~g}^{-1}$, and a progressive increase is observed for larger cerium-content samples, till the highest value of $14 \mathrm{~m}^{2} \mathrm{~g}^{-1}$ for the highest Ce-content sample $(x=0.9)$ is achieved. The obtained values for BET area of the calcined solids are in the range of previously reported for other lanthanum perovskites-type oxides $[15,16]$. It is worth mentioning, that not always a direct relation between BET surface area of the catalyst and the combustion rate of carbon black have been previously observed for this type of heterogeneous catalytic reaction $[2,7,17]$, since the catalytic combustion of soot takes place in the so-called triple contact point (catalyst-carbon black- $\mathrm{O}_{2}$ ), where the solid catalyst, the solid soot and the gaseous reactant meet together.

\section{$3.4 X$-ray diffraction $(X R D)$}

The samples calcined at $700^{\circ} \mathrm{C}$ (Fig.2, solid lines) with lower Ce content $\left(\mathrm{LaCoO}_{3}, \mathrm{La}_{0} \mathrm{Ce}_{01} \mathrm{CoO}_{3}\right)$ show well defined perovskite crystal structure, with sharp reflections and absence of any other crystalline phases. Cobaltite $\left(\mathrm{LaCoO}_{3}\right)$ belongs to a well crystallized rhombohedral structure ( JCPDF-480123) in agreement with previous results [18]. Moreover, two different behaviors can be detected as a function of the Ce content in the solids. For samples with lower Ce content $(x=0.1,0.3,0.5)$ the diffraction profiles indicate presence of the rhombohedral structure of $\mathrm{LaCoO}_{3}$ perovskite, with the appearance of a diffraction peak at $2 \theta=28.7^{\circ}$, attributed to segregated $\mathrm{CeO}_{2}$ phase. Only for the higher Ce content, $\geq 0.5$ it is also detected $\mathrm{Co}_{3} \mathrm{O}_{4}$ as segregated phase. It can be seen that the diffraction lines corresponding to $\mathrm{CeO}_{2}$ increases in line with the decrease of the diffraction peak at $2 \theta=33^{\circ}$ corresponding to the perovskite-type structure. Moreover, the decrease in intensity of the line at $2 \theta=33^{\circ}$ is accompanied with the disappearance of the characteristic doublet of the rhombohedral structure $\left(2 \theta\right.$ of $\left.33^{\circ}\right)$. It is noticeable no shift of the $2 \theta$ values, indicating no distortion of the perovskite structure upon Ce substitution, an expected result due to the similar ionic radii of $\mathrm{La}^{3+}$ and $\mathrm{Ce}^{3+} ; 0.136$ and $0.134 \mathrm{~nm}$ respectively. The diffraction patterns of larger Ce-content sample $(x=0.7,0.9)$ show: $i)$ absence of diffraction peaks attributed to the perovskite structure, which suggests that thermodynamic stability of perovskite structure is limited by the substitution degree of La by $\mathrm{Ce}$, regardless of the similarity between ionic radii of $\mathrm{La}^{3+}$ and $\mathrm{Ce}^{3+}$; ii) absence of diffraction peaks attributed to single or mixed lanthanum oxides; iii) appearance of two new crystalline phases that corresponds to $\mathrm{CeO}_{2}$ (JC-PDF 340394) and $\mathrm{Co}_{3} \mathrm{O}_{4}$ (JC-PDF 421467). The lack of lanthanum diffraction patterns can be taken as indicative of highly dispersed lanthanum oxide formation as a consequence of calcination at $700^{\circ} \mathrm{C}$; also the La oxide phase can be in an amorphous form or incorporated to $\mathrm{CeO}_{2}$. The XRD patterns of the calcined (solid lines) and the reduced (dotted lines) solids can be compared in Figure 2. Larger structure changes after $\mathrm{H}_{2}$ treatment at $700^{\circ} \mathrm{C}$ were observed for samples with lower Ce content $(x \leq 0.3)$, while calcined and reduced samples with higher Ce content $(x=0.7,0.9)$ show very similar XRD patterns. For the samples with lower Ce content $(\mathrm{x}=0.1,0.3$, $0.5)$ the most intense diffraction peak of the perosvkite-type structure $\left(2 \theta=33^{\circ}\right)$ fully disappears after reductive treatment, indicating a low thermal stability in $\mathrm{H}_{2}$ atmosphere. The diffraction lines of the reduced solids indicate the presence of $\mathrm{La}_{2} \mathrm{O}_{3}, \mathrm{La}_{2} \mathrm{CoO}_{4}, \mathrm{CeO}_{2}$ as segregated phases as well as $\mathrm{Co}^{\circ}$, which appears 
in the two broad peaks at $2 \theta=44.3^{\circ}$ and $51.5^{\circ}$, probably in a high dispersion degree. For $\mathrm{x} \geq 0.5$, a careful inspection of the diffraction profiles reveals no significant changes in the crystalline structure after hydrogen treatment and absence of diffraction lines belonging to single or mixed lanthanum oxides. Since the reduced samples with higher Ce content showed the higher catalytic activity for soot combustion, the effect of reductive treatment on the $\mathrm{CeO}_{2}$ mean crystal size was evaluated by using the Debye Scherrer equation. The diffraction line at $2 \theta=28.7^{\circ}$ was used to calculate the mean crystallite size of $\mathrm{CeO}_{2}$ and the results are shown in Figure 3. It is observed no effect of reductive treatment on the $\mathrm{CeO}_{2}$ crystal size for samples with low Ce content. Moreover, for calcined samples the $\mathrm{CeO}_{2}$ crystal size seems to be independent of the $\mathrm{Ce}$ content. On the contrary, the $\mathrm{CeO}_{2}$ particle size increases with the Ce content for higher-Ce-content samples after $\mathrm{H}_{2}$ treatment at $500^{\circ} \mathrm{C}$.

Table 2: Bulk composition (wt $\%$ ) and SS area for $\mathrm{La}_{1-\mathrm{x}} \mathrm{Ce}_{\mathrm{x}} \mathrm{CoO}_{3}$ catalysts.

\begin{tabular}{|c|c|c|c|c|c|c|}
\hline & \multirow{2}{*}{$\mathrm{x}_{\mathrm{Ce}}$} & $\mathrm{La}^{1}$ & $\mathrm{Ce}^{1}$ & \multicolumn{2}{|c|}{$\mathrm{Co}^{1}$} & \multicolumn{2}{|c|}{$\mathrm{S}_{\mathrm{BET}}, \mathrm{m}^{2} \mathrm{~g}^{-1}$} \\
\hline $\mathrm{LaCoO}_{3}$ & 0.0 & $55.8(56.5)$ & --- & $24.2(24.0)$ & 10 & 7 \\
\hline $\mathrm{La}_{0.9} \mathrm{Ce}_{0.1} \mathrm{CoO}_{3}$ & 0.1 & $50.2(50.8)$ & $4.9(5.7)$ & $24.4(24.0)$ & 10 & 7 \\
\hline $\mathrm{La}_{0.7} \mathrm{Ce}_{0.3} \mathrm{CoO}_{3}$ & 0.3 & $39.1(39.5)$ & $16.9(17.1)$ & $24.0(23.9)$ & 14 & 10 \\
\hline $\mathrm{La}_{0.5} \mathrm{Ce}_{0.5} \mathrm{CoO}_{3}$ & 0.5 & $26.9(28.2)$ & $27.9(28.4)$ & $23.5(23.9)$ & 15 & 11 \\
\hline $\mathrm{La}_{0.3} \mathrm{Ce}_{0.7} \mathrm{CoO}_{3}$ & 0.7 & $15.8(16.9)$ & $40.3(39.8)$ & $23.6(23.9)$ & 18 & 12 \\
\hline $\mathrm{La}_{0.1} \mathrm{Ce}_{0.9} \mathrm{CoO}_{3}$ & 0.9 & $6.3(5.6)$ & $50.9(51.1)$ & $22.9(23.9)$ & 19 & 14 \\
\hline
\end{tabular}

${ }^{1}$ Estimated error is below 1\% (Nominal values are in parentheses)
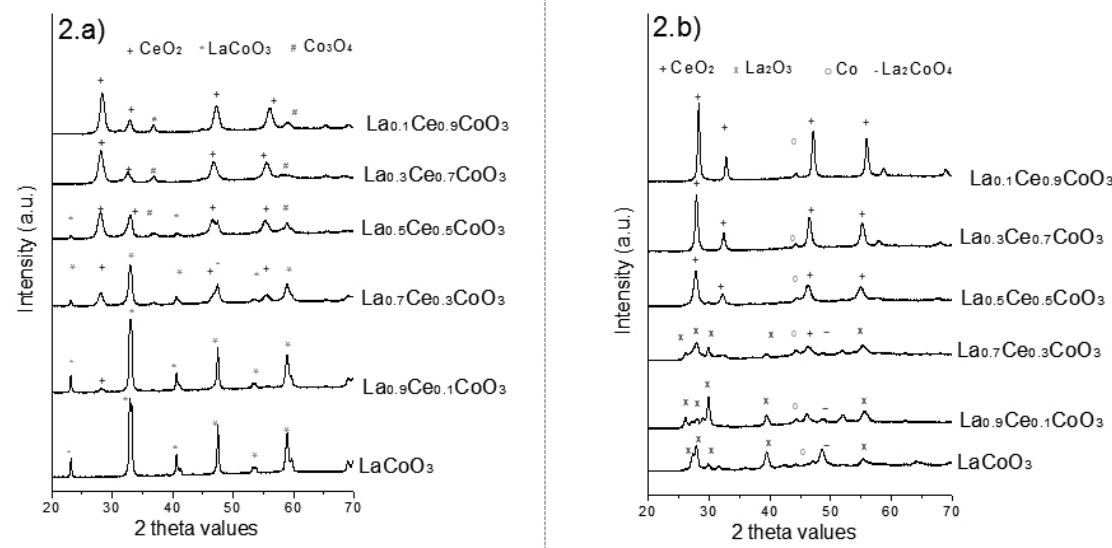

Figure 2. XRD profiles for $\mathrm{La}_{1-\mathrm{x}} \mathrm{Ce}_{\mathrm{x}} \mathrm{CoO}_{3}$ catalysts: a) calcined; b) reduced.

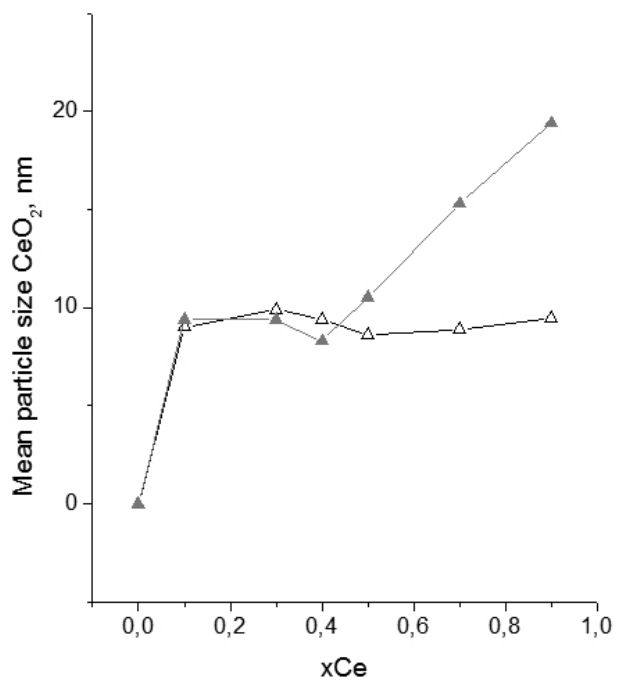

Besides surface area and crystalline structure characterizations, the surface redox properties of the catalysts, i.e., reducibility (TPR) and surface oxygen stability (TPD- $\mathrm{O}_{2}$ ) were also measured, since these properties have shown to be closely related with the catalytic activity for soot combustion [19].

3.5 Temperature-Programmed Reduction (TPR)

The temperature-programmed reduction profiles (TPR) shown in Figure 4 indicate that for pure $\mathrm{LaCoO}_{3}$ the reduction process does not occur in a single step. The first reduction peak at $365^{\circ} \mathrm{C}$ corresponds to an intermediate oxygendeficient perovskite structure $\left(\mathrm{LaCoO}_{3 .}\right)$ and the complete reduction of the perovskite, with formation of $\mathrm{La}_{2} \mathrm{O}_{3}, \mathrm{La}(\mathrm{OH})_{3}, \mathrm{H}_{2} \mathrm{O}$ and $\mathrm{Co}^{\circ}$ corresponds to the second reduction peak at $530^{\circ} \mathrm{C}$ [20]. The one at lower temperatures is attributed to surface oxygen species, while the reduction of the cobaltite structure $\left(\mathrm{LaCoO}_{3}=1 / 2 \mathrm{La}_{2} \mathrm{O}_{3}+\mathrm{CoO}+1 / 4 \mathrm{O}_{2}\right)$ occurs at higher reduction temperature. Upon Ce content, broader peaks with a progressive decrease in the reduction temperature of cobalt with the reduction of cerium between the two reduction peaks of cobalt can be clearly seen in Figure 4. The shift of the reduction peaks to lower temperatures implies an increase in the reducibility of the catalysts. Since soot oxidation, is a redox reaction, it is expected that the enhancement of the low-reducibility of the catalysts must have a positive effect in the catalytic activity to the soot combustion.

Figure 3. $\mathrm{CeO}_{2}$ mean particle size for $\mathrm{La}_{1-\mathrm{x}} \mathrm{Ce}_{\mathrm{x}} \mathrm{CoO}_{3}$ catalysts. $(\Delta)$ calcined; $(\boldsymbol{\Delta})$ reduced 


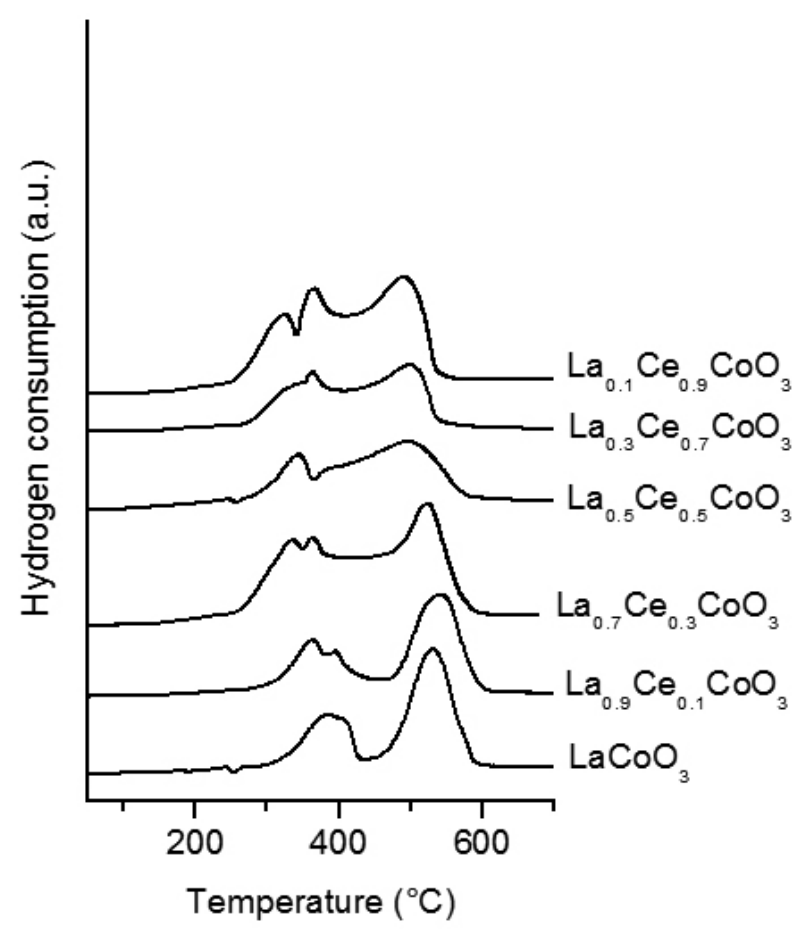

Figure 4. Temperature-programmed reduction profiles for $\mathrm{La}_{1-\mathrm{x}} \mathrm{Ce}_{\mathrm{x}} \mathrm{CoO}_{3}$ catalysts.

3.6 Oxygen-Temperature Programmed Desorption $\left(\mathrm{O}_{2}-\mathrm{TPD}\right)$

The evolution of oxygen during temperature-programmed desorption $\left(\mathrm{O}_{2}\right.$-TPD) experiments are also closely related to the redox properties of the catalysts[21]. It is well known that depending on the oxygen desorption temperatures, physical, $\alpha$-oxygen's and $\beta$-oxygen's can be detected. Physical oxygen's correspond to the low desorption peak centered at $\square 80^{\circ} \mathrm{C}$, which comes likely from weakly held oxygen species. The namely $\alpha$-oxygen's are ascribed to adsorbed oxygen at oxygen vacancies that desorbs between $200^{\circ} \mathrm{C}$ to $500^{\circ} \mathrm{C}$ [22] and the so-called $\beta$-oxygen associated with the lattice oxygen desorbs up to $600^{\circ} \mathrm{C}$ with partial reduction of the $\mathrm{B}$ site metal to lower oxidation state[23]. These desorbed oxygen species are of less importance in soot combustion since the reaction occurs at lower temperature. Figure 5 displays the obtained $\mathrm{O}_{2}$-TPD profiles. The large desorption peaks located at $\sim 90^{\circ} \mathrm{C}$ indicates the presence of weakly physisorbed oxygen species, with no dependence of the Ce content and not related with catalytic activity. Meanwhile, a beneficial effect in the $\alpha$-oxygen's can be related with the Ce content. The importance of the surface oxygen's species is their close relation with the oxygen vacancies in the perovskite structure, that can activate the molecular oxygen forming active oxygen species in the $\mathrm{ABO}_{3}$ structure[24]. Since TPDMS experiments confirm that the evolved gas and the He flow only contain oxygen, the deconvolution of the oxygen desorption curves using a Lorentzian peak shape allow to calculate the amount of desorbed oxygen. The obtained profiles were deconvoluted and only the desorbed oxygen corresponding to the $\alpha$-oxygens are displayed in Table 3 . It can be seen a continuous increase with Ce content. The larger activity of the higher Ce substituted catalysts indicates availability of reactive oxygen species on the catalytic surface, attributed to the weaker oxygen binding [25]. In this way, it is proposed that the gaseous oxygen may be dissociatively adsorbed on the surface of the metal oxide forming an oxygen adsorbed species that can react with the reactive free carbon site to give a highly reactive oxygen-carbon intermediate which can react either with the $\mathrm{O}_{\text {ads }}$ or gaseous $\mathrm{O}_{2}$ to form $\mathrm{CO}$ or $\mathrm{CO}_{2}[26]$. In the catalytic oxidation reaction using mixed oxides or perovskites types oxides as catalysts, the oxygen surface oxygen species $\left(\mathrm{O}^{-}, \mathrm{O}_{2}^{-}, \mathrm{O}^{2-}\right)$ involved in the catalytic process may come from the molecular oxygen in gas phase, surface oxygen's or lattice oxygen. The promotional effect of ceria on cobaltite explain the catalytic effect in these catalysts, in line with previous results reporting that structural defects and oxygen mobility are important factors controlling the catalytic activity of these type of crystalline structures [27].The larger catalytic activity of the two catalysts with larger $\mathrm{Ce}$ content $(\mathrm{x}=0.7$ and 0.9$)$ is in agreement with previous result of the enhanced in the catalytic soot oxidation by lattice oxygen via $\mathrm{La}^{3+}$ doped $\mathrm{CeO}_{2}$ in the $\mathrm{CeO}_{2}$ /soot interface [28-30].
Table 3: Detected XRD phases and desorbed oxygen for $\mathrm{La}_{1-\mathrm{x}} \mathrm{Ce}_{\mathrm{x}} \mathrm{CoO}_{3}$ catalysts.

\begin{tabular}{|c|c|c|c|c|}
\hline & \multirow{2}{*}{$\mathrm{x}_{\mathrm{Ce}}$} & \multicolumn{2}{|c|}{ Detected XRD phases } & \multirow{2}{*}{$\mu \mathrm{molO}_{2} \mathrm{~g}^{-1}$} \\
\hline & & calcined & reduced & \\
\hline $\mathrm{LaCoO}_{3}$ & 0.0 & $\mathrm{LaCoO}_{3}$ & $\mathrm{La}_{2} \mathrm{O}_{3} \mathrm{Co}$ & 183 \\
\hline $\mathrm{La}_{0.9} \mathrm{Ce}_{0.1} \mathrm{CoO}_{3}$ & 0.1 & $\mathrm{LaCoO}_{3} \mathrm{CeO}_{2}$ & $\begin{array}{c}\mathrm{La}_{2} \mathrm{O}_{3} \mathrm{CeO}_{2} \\
\mathrm{Co}\end{array}$ & 161 \\
\hline $\mathrm{La}_{0.7} \mathrm{Ce}_{0.3} \mathrm{CoO}_{3}$ & 0.3 & $\begin{array}{c}\mathrm{LaCoO}_{3} \mathrm{CeO}_{2} \\
\mathrm{Co}_{3} \mathrm{O}_{4}\end{array}$ & $\begin{array}{c}\mathrm{La}_{2} \mathrm{O}_{3} \mathrm{CeO}_{2} \\
\mathrm{Co}\end{array}$ & 267 \\
\hline $\mathrm{La}_{0.5} \mathrm{Ce}_{0.5} \mathrm{CoO}_{3}$ & 0.5 & $\begin{array}{c}\mathrm{LaCoO}_{3} \mathrm{CeO}_{2} \\
\mathrm{Co}_{3} \mathrm{O}_{4}\end{array}$ & $\mathrm{CeO}_{2} \mathrm{Co}$ & 278 \\
\hline $\mathrm{La}_{0.3} \mathrm{Ce}_{0.7} \mathrm{CoO}_{3}$ & 0.7 & $\mathrm{CeO}_{2} \mathrm{Co}_{3} \mathrm{O}_{4}$ & $\mathrm{CeO}_{2} \mathrm{Co}$ & 317 \\
\hline $\mathrm{La}_{0.1} \mathrm{Ce}_{0.9} \mathrm{CoO}_{3}$ & 0.9 & $\mathrm{CeO}_{2} \mathrm{Co}_{3} \mathrm{O}_{4}$ & $\mathrm{CeO}_{2} \mathrm{Co}$ & 366 \\
\hline
\end{tabular}

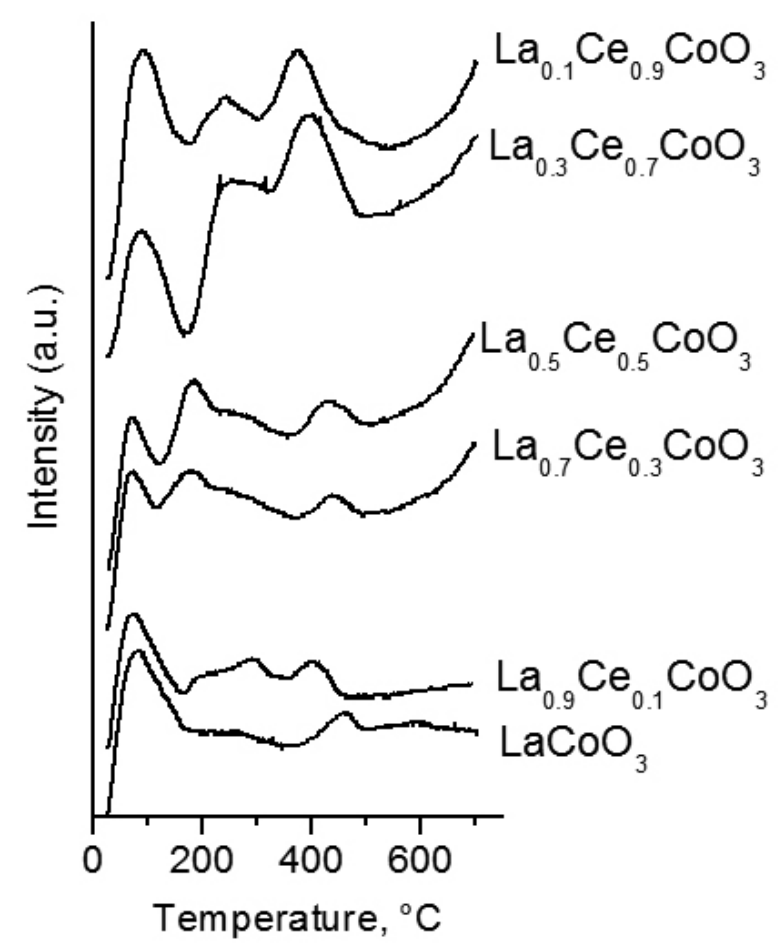

Figure 5. Oxygen desorption profiles for $\mathrm{La}_{1-\mathrm{x}} \mathrm{Ce}_{\mathrm{x}} \mathrm{CoO}_{3}$ catalysts.

\section{DISCUSSION}

All samples tested in this study show significant catalytic activity for soot combustion. Perovskite $\mathrm{LaCoO}_{3}$ and low-Ce-content samples $(x \leq 0.5)$ with well-defined perovskite-type structure (Fig 2) reduce the Tm value in more than $200^{\circ} \mathrm{C}$. However, this catalytic activity practically did not change after perovskite structure destruction with sample reductive treatment at $500^{\circ} \mathrm{C}$ (Fig 1). These results are inconsistent with the catalytic role attributed to perovskitetype structures and hardly support the recently proposed mechanism for soot combustion on lanthanoid perovskites, in which the oxidation of soot particles is attributed to the surface oxygen species, which migrate from the perovskite structure $[31,32]$. Moreover, Fig 1 shows a higher catalytic activity for calcined samples with higher Ce content $(\mathrm{x}=0.7,0.9)$, in which XRD patterns show $\mathrm{CeO}_{2}$ and $\mathrm{Co}_{3} \mathrm{O}_{4}$ crystal phases instead of perovskite-type structure. These results suggest that $\mathrm{CeO}_{2}$ is playing the main role in soot combustion, which is in agreement with the higher catalytic activity of ceria oxide reported for soot combustion [33]. Moreover, the oxygen storage capacity of samples increases with Ce content as observed in Fig 5. Since XRD patterns (Fig 2) show an increase in the intensity of $\mathrm{CeO}_{2}$ peaks with Ce content, it is inferred that $\mathrm{CeO}_{2}$ crystals directly participates in the oxygen storage and exchange 
process. It is also important to note that $\mathrm{H}_{2}$ reduction process (destruction of perovskite-type structure) increases the catalytic activity for all the samples but in a different degree; samples with low $\mathrm{CeO}_{2}$ content $(\mathrm{x} \leq 0.5)$ slightly increased their activity while samples with higher amount of $\mathrm{CeO}_{2}(\mathrm{x}=0.7,0.9)$ strongly increased the activity for soot combustion after reductive process. Also, reduced samples with higher $\mathrm{Ce}$ content $(\mathrm{x}=0.7-0.9)$ show an increase in $\mathrm{CeO}_{2}$ mean crystal size as shown in Fig 3. The same phenomenon was not observed for the calcined samples, in which the $\mathrm{CeO}_{2}$ particle size was insensible to $\mathrm{Ce}$ sample content increasing. These results suggest that the activity of these materials for soot combustion is improved by two factors: i) the increasing of $\mathrm{CeO}_{2}$ content and ii) the formation of larger $\mathrm{CeO}_{2}$ crystals in the higher-Ce-content samples after $\mathrm{H}_{2}$ reduction. In fact, it was observed a similar $\mathrm{CeO}_{2}$ mean particle size for all calcined samples, while the catalytic activity increases with the $\mathrm{Ce}$ content as a consequence of a larger $\mathrm{CeO}_{2}$ total surface, in which the oxygen can be activated and transferred to CB surface through more abundant catalyst$\mathrm{CB}$ contact points. In the same way, the catalytic activity of reduced samples is improved by the increasing of $\mathrm{CeO}_{2}$ amount, but additionally, larger $\mathrm{CeO}_{2}$ crystals were formed in the samples with higher Ce content $(x=0.7-0.9)$, which could explain the stronger decrease of Tm values when these samples were used as catalyst for soot combustion. Catalytic activity for soot combustion is closely related to higher material capacity for oxygen transfer from catalyst to carbonaceous surface[34]. Thus, the higher amount of $\mathrm{CeO}_{2}$ crystals in the sample, the higher oxygen storage in the catalytic surfaces and more contact point between catalyst and $\mathrm{CB}$, through which active oxygen species attack the carbon material. This explains the reducing of $\mathrm{Tm}$ value with the increasing of $\mathrm{CeO}_{2}$ content for all the tested samples. Since XRD patterns (Fig. 2) show the presence of $\mathrm{Co}_{3} \mathrm{O}_{4}$ in calcined samples with higher Ce content $(\mathrm{x}=0.7-0.9)$, the effect of cobalt oxide is not disregarded, however, the cobalt oxide composition in both samples is the same, so this work does not provides evidences to attribute the observed catalytic activity for soot combustion to this specific phase. The reduction processes with $\mathrm{H}_{2}$ neither reduce the $\mathrm{CeO}_{2}$ to metallic $\mathrm{Ce}$ nor affect the Ce material composition; however, this treatment did cause dissimilar increasing of catalytic activity as a function of sample Ce content. Fig. 1 demonstrates that reduced samples with lower Ce content $(x \leq 0.5)$ showed a minor improvement of catalytic activity than high-Ce-content samples $(x=0.7-$ 0.9 )(Fig.1), as a result of the increasing of $\mathrm{CeO}_{2}$ crystal size in these samples (Fig. 3). These results confirm that cerium oxide represents the main active phase in these materials, so the higher catalytic activity for soot combustion is related to an increase in the $\mathrm{CeO}_{2}$ sample content, which improves the oxygen exchange and number of contact points between catalyst and soot. Additionally, our results provide evidences of structural sensitivity of active oxygen species formation over $\mathrm{CeO}_{2}$, since larger $\mathrm{CeO}_{2}$ crystals showed higher activity for $\mathrm{CB}$ combustion than smaller ones, for comparison between samples with the same $\mathrm{CeO}_{2}$ composition. Afterward, the formation of active oxygen species and their transfer from $\mathrm{CeO}_{2}$ to carbonaceous material seems to be favored in large crystals rather than small ones, since a higher availability of lattice oxygen for oxygen exchange with gas phase is expected in larger crystal faces than in edges and corner, the later proportionally more abundant in small particles. Moreover, the transfer of oxygen species from edges and corners of $\mathrm{CeO}_{2}$ crystals would be affected by the stronger binding of oxygen atoms. Bueno-López et al. $[29,30]$ used labeled $\left(\mathrm{O}^{18}\right)$ in gas phase and non labeled $\left(\mathrm{O}^{16}\right)$ in catalysts to probe that the gas-phase labeled oxygen replaces non labeled lattice oxygen, creating the highly active non labeled oxygen, which reacts with soot, giving $\mathrm{CO}$ and $\mathrm{CO}_{2}$. In this sense, our results not only indicate that this highly active oxygen is more abundant in those samples with higher $\mathrm{CeO}_{2}$ content, but also suggest that the reactivity of this oxygen species increase with the $\mathrm{CeO}_{2}$ crystal size. Bueno-López et al.[30] observed an important improvement of catalytic activity when $\mathrm{CeO}_{2}$ was doped with $\mathrm{La}$. The authors relate this result with a decrease in the onset temperature at which $\mathrm{Ce}^{4+}$ is reduced to $\mathrm{Ce}^{3+}$, i.e. the doping with $\mathrm{La}$ increases $\mathrm{Ce}$ reducibility. The effect of $\mathrm{La}$ doping on $\mathrm{CeO}_{2}$ catalytic activity for soot combustion is not disregarded in this work, since $\mathrm{La}$ is present in smaller amount in those samples with higher catalytic activity (reduced $\mathrm{x}>$ 0.5 ). However, our results do not have strong evidences to support this idea.

\section{CONCLUSIONS}

$\mathrm{La}_{1-\mathrm{x}} \mathrm{Ce}_{\mathrm{x}} \mathrm{CoO}_{3}$ catalysts were synthesized, characterized and evaluated for the soot combustion. It was found an increase in the specific area upon $\mathrm{Ce}$ content. Since the ionic radii of cerium is similar to lanthanum, cerium can be introduced to the lattice for the substitution $\mathrm{x} \leq 0.5$, while for larger Ce content $(\mathrm{x} \geq 0.7)$ formation of $\mathrm{CeO}_{2}$ phase is detected. The destruction of the perovskitetype structure in a reductive process increases the catalytic activity in a differ- ent degree; a slightly increased in the samples with low $\mathrm{CeO}_{2}$ content $(\mathrm{x} \leq 0.5)$ while those with higher amount of $\mathrm{CeO}_{2}(\mathrm{x}=0.7,0.9)$ strongly increased their activity for soot combustion. These results suggest that the activity of these materials for soot combustion is improved by two factors: i) the increasing of $\mathrm{CeO}_{2}$ content, closely related to higher material capacity for oxygen transfer from catalyst to carbonaceous surface and ii) the formation of larger $\mathrm{CeO}_{2}$ crystals in the higher-Ce-content samples after $\mathrm{H}_{2}$ reduction, responsible for the improvement of the oxygen exchange and number of contact points between catalyst and soot.

\section{ACKNOWLEDGEMENTS}

The authors thank CONICYT (Fondecyt Grant 1130005), Red Doctoral REDOC, MINEDUC project UCO1202 and Grant PFB-27.

\section{REFERENCES}

[1] J.O. Uchisawa, A. Obuchi, Z. Zhao, S. Kushiyama, Applied Catalysis B-Environmental, 18 (1998) L183-L187.

[2] R. Jimenez, X. Garcia, T. Lopez, A.L. Gordon, Fuel Processing Technology, 89 (2008) 1160-1168.

[3] M.A. Peralta, V.G. Milt, L.M. Cornaglia, C.A. Querini, Journal of Catalysis, 242 (2006) 118-130.

[4] Q. Li, M. Meng, F.F. Dai, Y.Q. Zha, Y.N. Xie, T.D. Hu, J. Zhang, Chemical Engineering Journal, 184 (2012) 106-112.

[5] Z.Q. Li, M. Meng, F.F. Dai, T.D. Hu, Y.N. Xie, J. Zhang, Fuel, 93 (2012) 606-610.

[6] G. Pecchi, B. Cabrera, A. Buljan, E.J. Delgado, A.L. Gordon, R. Jimenez, Journal of Alloys and Compounds, 551 (2013) 255-261.

[7] G. Pecchi, B. Cabrera, E.J. Delgado, X. Garcia, R. Jimenez, Applied Catalysis a-General, 453 (2013) 341-348.

[8] K. Taniguchi, N. Okinaka, T. Akiyama, Journal of Alloys and Compounds, 509 (2011) 4084-4088.

[9] D. Fino, N. Russo, G. Saracco, V. Speechia, Journal of Catalysis, 217 (2003) $367-375$

[10]P. Doggali, H. Kusaba, S. Rayalu, Y. Teraoka, N. Labhsetwar, Topics in Catalysis, 56 (2013) 457-461.

[11]R.D. Zhang, N. Luo, B.H. Chen, S. Kaliaguine, Energy \& Fuels, 24 (2010) 3719-3726.

[12]G. Pecchi, C. Campos, O. Pena, Materials Research Bulletin, 44 (2009) 846-853.

[13]L.A. Chick, L.R. Pederson, G.D. Maupin, J.L. Bates, L.E. Thomas, G.J. Exarhos, Materials Letters, 10 (1990) 6-12.

[14]B. Jankovic, B. Adnadevic, S. Mentus, Chemical Engineering Science, 63 (2008) $567-575$

[15]N. Russo, D. Fino, G. Saracco, V. Specchia, Journal of Catalysis, 229 (2005) 459-469

[16] N.A. Merino, B.P. Barbero, P. Grange, L.E. Cadús, Journal of Catalysis, 231 (2005) 232-244.

[17]D. Fino, P. Fino, G. Saracco, V. Specchia, Applied Catalysis B-Environmental, 43 (2003) 243-259.

[18]K. Poplawski, J. Lichtenberger, F.J. Keil, K. Schnitzlein, M.D. Amiridis, Catalysis Today, 62 (2000) 329-336.

[19]D. Fino, N. Russo, E. Cauda, G. Saracco, V. Specchia, Catalysis Today, 114 (2006) 31-39.

[20] G. Pecchi, C. Campos, O. Pena, L.E. Cadus, Journal of Molecular Catalysis a-Chemical, 282 (2008) 158-166.

[21]H.M. Zhang, Y. Shimizu, Y. Teraoka, N. Miura, N. Yamazoe, Journal of Catalysis, 121 (1990) 432-440.

[22]S. Ifrah, A. Kaddouri, P. Gelin, G. Bergeret, Catalysis Communications, 8 (2007) $2257-2262$.

[23]R.D. Zhang, A. Villanueva, H. Alamdari, S. Kaliaguine, Journal of Catalysis, 237 (2006) 368-380.

[24] G. Pecchi, P. Reyes, R. Zamora, C. Campos, L.E. Caduus, B.P. Barbero, Catalysis Today, 133 (2008) 420-427.

[25]D.V. Ivanov, L.G. Pinaeva, E.M. Sadovskaya, L.A. Isupova, Kinetics and Catalysis, 52 (2011) 401-408

[26] M.J. Illan-Gomez, C.S.M. de Lecea, A. Linares-Solano, L.R. Radovic, Energy \& Fuels, 12 (1998) 1256-1264.

[27]L. Marchetti, L. Forni, Applied Catalysis B-Environmental, 15 (1998) 179-187.

[28] M. Machida, Y. Murata, K. Kishikawa, D.J. Zhang, K. Ikeue, Chemistry of Materials, 20 (2008) 4489-4494. 
[29]A. Bueno - Lopez, K. Krishna, M. Makkee, J. Moulijn, Catalysis Letters, 99 (2005) 203-205.

[30] A. Bueno-Lopez, K. Krishna, M. Makkee, J.A. Moulijn, Journal of Catalysis, 230 (2005) 237-248.

[31] M.L. Fu, X.H. Yue, D.Q. Ye, J.H. Ouyang, B.C. Huang, J.H. Wu, H. Liang, Catalysis Today, 153 (2010) 125-132.
[32] X.H. Yue, X. Zhang, M.L. Fu, B.C. Huang, H. Liang, D.Q. Ye, Chinese Journal of Inorganic Chemistry, 25 (2009) 1170-1176.

[33]E. Aneggi, J. Llorca, C. de Leitenburg, G. Dolcetti, A. Trovarelli, Applied Catalysis B-Environmental, 91 (2009) 489-498

[34] R. Jimenez, R. Zamora, G. Pecchi, X. Garcia, A.L. Gordon, Fuel Processing Technology, 91 (2010) 546-549. 